\title{
Pregled dosežkov madžarske slovenistike po letu 1990
}

\author{
Alma VÁrkonyi \\ Univerza Loránda Eötvösa, Filozofska fakulteta, ELTE BTK, \\ Múzeum krt.4/D, HU-1088 Budapest, varkonyialma@gmail.com
}

\begin{abstract}
$\mathrm{V}$ zadnjih dveh desetletjih je na Madžarskem nastala bogata literatura na področju slovensko-madžarskih literarnih, jezikovnih ter kulturnih stikov. Prispevek poskuša predstaviti znanstvene dosežke madžarske slovenistike - literarne zgodovine, jezikoslovja, zgodovine ter kulturne zgodovine -, leposlovno in znanstveno knjižno produkcijo slovenske manjšine na Madžarskem ter madžarske prevode slovenskih leposlovnih del, nastale od leta 1990.
\end{abstract}

In the last 20 years, the research of Sloveno-Hungarian literary, linguistic and cultural connections has been very fruitful. The following paper aims to presents the most important publications related to the Slovene culture issued after 1990, including but not limited to the scientific publications on Slovene Studies (including the papers on Literary History, Linguistics, History and History of Culture), the literary and scientific publications of the Hungarian Slovene minority and the Hungarian translations of the Slovene literature.

Ključne besede: slovenistika, slovensko-madžarski jezikovni in književni stiki, zgodovina, slovaropisje, Slovenci na Madžarskem, prevajanje leposlovja

Keywords: Slovene Studies, Sloveno-Hungarian literary and linguistic connections, Slovenes in Hungary, history, lexicography, artistic translation

\section{Uvod}

Marjanca Mihelič (1990), takratna lektorica slovenskega jezika v Budimpešti - njena razprava je bila prevedena tudi v madžarščino (Mihelič 1998) -, obravnava zgodovino madžarske slovenistike od Avgusta Pavla do konca osemdesetih let dvajsetega stoletja. Leta 1998 je Pavičić (1998: 141-143), sedanji 
slovenski lektor v Budimpešti, objavil zgodovino poučevanja slovenščine na budimpeštanski slavistiki in predstavil pomembnejše slovenistične dogodke na Madžarskem do leta 1998. Orcsik (2010), ki se ukvarja s srbsko-hrvaško-slovensko-madžarskimi literarnimi stiki v 20. stoletju, je predstavil madžarske raziskave s področja slovenske književnosti in naštel nekatere novejše madžarske prevode slovenskega leposlovja. Kljub temu pa po Miheličevi ni več bilo dela, ki bi se osredinilo na dosežke madžarske slovenistike ter prevode leposlovja.

Gradivo za članek sem zbrala v Széchényijevi državni knjižnici, Državni knjižnici za tuje jezike in knjižnici Madžarske akademije znanosti, v Sloveniji pa sem uporabljala kataloge Narodne in univerzitetne knjižnice ter Osrednje humanistične knjižnice Filozofske fakultete Univerze v Ljubljani; upoštevala sem znanstvene bibliografije madžarskih slovenistov, profesorjev slovenistike, pri pregledu prevodov tudi seznam slovenskega leposlovja $\mathrm{v}$ madžarskem jeziku. ${ }^{1}$ Za celotno podobo o zanimanju Madžarov za Slovence in slovensko kulturo pa je bilo potrebno upoštevati tudi nekatera dela zgodovinsko-politično-družbene vsebine, ki se ukvarjajo s spremembami ob razpadu Jugoslavije ter z nastankom samostojne in neodvisne Slovenije.

\section{Slovensko-madžarski literarni, jezikovni in kulturni stiki}

Strokovna literatura, ki se ukvarja s slovensko-madžarskimi književnimi, jezikovnimi in kulturnimi stiki, je obsežna, saj so bili v zadnjih dvajsetih letih organizirani številni simpoziji, konference in posvetovanja. Leta 1990 je Oddelek za madžarski jezik in književnost Pedagoške fakultete Univerze v Mariboru organiziral znanstveno posvetovanje ob 500-letnici smrti kralja Matjaža, na katerem so znanstveniki ovrednotili lik kralja Matjaža v madžarsko-južnoslovanskih stikih iz literarno-zgodovinskega, kulturno-zgodovinskega in etnološkega vidika (Varga, Molnár 1991) - med predavatelji so bili tudi madžarski slovenisti István Lukács, István Fried in Károly Gadány, posvetovanja pa sta se udeležila tudi Vlado Nartnik in Marjanca Mihelič, nekdanja slovenska lektorja na budimpeštanski slavistiki, hungarolog in predstojnik Oddelka za madžarski jezik in književnost v Mariboru, József Bokor, pa je obravnaval vprašanja jezikovnih stikov in prevajanja. Dvojezični zbornik razprav je izšel v Mariboru s sodelovanjem Oddelka za slavistiko sombotelske Visoke učiteljske šole Dániela Berzsenyija. V organizaciji obeh inštitutov je leta 2000 potekala konferenca Szomszéd népek - szomszédos kultúrák (Sosednji narodi - sosednje kulture), zbornik z istim naslovom (Bokor, Szijártó 2001) pa je prinesel gradivo s konference $v$ slovenskem in madžarskem jeziku. Prireditev se je osredotočila na literarni regionalizem ter slovensko-madžarske literarne in kulturne stike, razprave pa so bile razvrščene $\mathrm{v}$ štiri tematske sklope $-\mathrm{v}$ prvem delu so predstavljena literarnozgodovinska in komparativna

\footnotetext{
${ }^{1}$ vir: http://szlavintezet.elte.hu/szlavtsz/szloven/irodalom.shtml (datum: 25. 03. 2012)
} 
vprašanja, $v$ drugem duhovni stiki in medsebojni vplivi, $v$ tretjem recepcija sodobnih literatur, v četrtem pa manjšinska književnost. Prispevka Istvána Lukácsa in Istvána Frieda obravnavata zgodovino slovenske književnosti v luči madžarske literarne zgodovine, István Lőkös predstavlja intelektualno-duhovno vzdušje Sombotela v času Jožefa Košiča, Orsolya Gállos analizira spremembe zgodovinske tematike v madžarski in slovenski prozi od leta 1970 naprej, Marjanca Mihelič pa se dotakne vprašanj prevajanja sodobne madžarske književnosti v slovenščino.

Košičev sklad in Slavistični oddelek Filozofske fakultete Univerze Loránda Eötvösa sta leta 1997 organizirala znanstveno posvetovanje Slovensko-madžarski jezikovni in književni stiki od Košiča do danes. Zbornik razprav je izšel leta 1998 (Nyomárkay, Lukács 1998). Prispevki so razvrščeni po tematiki v dve večji poglavji. Prvo poglavje je posvečeno jezikovnim, drugo pa književnim stikom. Prispevki s področja jezikovnih stikov se ukvarjajo z vprašanji in zgodovino prekmurskega knjižnega jezika ter z medsebojnimi vplivi madžarskega in slovenskega jezika. Književne študije obravnavajo prekmursko in porabsko slovstvo, slovensko-madžarske literarne vzporednice ter vprašanja prevajanje. Med avtorji so predstavniki madžarske in slovenske slavistike ter slovenistike: István Nyomárkay, Károly Gadányi, István Lukács, István Fried, István Lőkös, Orsolya Gállos, Marija Kozár-Mukič, Martina Orožen, Zinka Zorko, Elizabeta Bernjak, Marko Jesenšek, Majda Potrata, Jožica Čeh, Vlado Nartnik, Mladen Pavičić, Irena Stramljič, Marija Jež, Zoltán Miklós Molnár, Ibolya Doncsecz ter Marija Sulics Leskovar.

Istega leta je Košičev sklad izdal dvojezični zbornik Ujemanja in razhajanja (Lukács, Fried 1998). V knjigi so zbrane že objavljene študije o slovenskomadžarskih literarnih stikih s področja recepcije, komparatistike, literarnih vzporednic ter prevajanja. Izmed štirih poglavij je posebno poglavje posvečeno motivu kralja Matjaža v slovenski književnosti.

Lik kralja Matjaža je pomembno stičišče v kulturni zgodovini Slovencev in Madžarov. István Lukács je leta $2001 \mathrm{v}$ znanstveni monografiji A megváltó Mátyás király szineváltozásai a szlovén néphagyományban és szépirodalomban (Preobrazbe odrešitelja kralja Matjaža v slovenskem ljudskem izročilu in $\mathrm{v}$ leposlovju) predstavil recepcijo motiva kralja Matjaža v slovenski literaturi. $\mathrm{V}$ prvem poglavju je prikazal zgodovinski pregled in vlogo Matije Korvina na slovenskem ozemlju, v drugem poglavju pa se je osredotočil na izoblikovanje Matjaževega mita in na interpretacijo Matjaževega lika v slovenskem ljudskem izročilu; v tretjem, najobsežnejšem poglavju je analiziral recepcijo mita v slovenskem leposlovju, in sicer od aktualizacije mita v času Prešerna in Aškerca do Matjaževe demitizacije na prelomu 19. in 20. stoletja in do končne faze razvoja motiva v poeziji Karla Destovnika - Kajuha (Lukács 2001: 106). Četrto poglavje predstavlja idejno in poetično sintezo Matjaževega mita v literarnem delu Ivana Cankarja.

Raziskovanje slovensko-madžarskih kulturnih stikov je bilo v 90-ih letih prejšnjega stoletja tesno povezano tudi z zanimanjem za življenje in delo gornjeseniškega duhovnika Jožefa Košiča. Prvi rezultat tega raziskovalnega dela 
je bila zbirka Življenje Slovencev med Muro in Rabo (Bajzek 1992), ki vsebuje ponatisnjene Košičeve izbrane spise. V celoti sta objavljena Košičevo etnološko delo O Slovencih na Ogrskem v knjižnoslovenskem prevodu in didaktični spis Zobrisani Sloven i Slovenka med Mürov i Rábov. Za delno objavo se je urednica odločila pri delih Zgodbe Vogerskoga Králestva ter Starine Železnih ino Salaskih Slovenov. Predstavljeni so tudi nekateri deli Košičevega prevoda madžarske slovnice Krátki Návuk Vogrskoga Jezika. Zbirka je dala pobudo za nadaljnje raziskave in znanstveno delo, med drugim tudi za organizacijo simpozija Košič in njegov čas v Števanovcih, ki ga je leta 1993 organiziral Košičev sklad - naslednje leto je izšel tudi zbornik (Zorko, Bajzek, Lukács 1994) s prispevki slovenskih in madžarskih strokovnjakov, ki so obravnavali Košičevo ustvarjalno delo, njegov jezik, njegovo življenje in čas, $v$ katerem je živel (Zorko, Bajzek, Lukács 1994: 5).

Tematiki slovensko-madžarskih književnih stikov je posvečena knjiga Közel s távol (Lukács 2005). V monografiji, ki je izšla v zbirki Oddelka za slovansko filologijo Filozofske fakultete Univerze Loránda Eötvösa Opera Slavica Budapestinensia Litterae Slavicae, so zbrane avtorjeve slovenskomadžarske literarnozgodovinske študije, večinoma že objavljene v različnem času v strokovni periodiki in različnih zbornikih. V prvem poglavju sta študiji o recepciji slovenske književnosti na Madžarskem, drugo poglavje vsebuje prispevke o recepciji madžarske literature na Slovenskem, tretje pa obravnava življenje in delo treh pomembnih slovenskih osebnosti: Jožefa Košiča, Franceta Prešerna in Ivana Cankarja. Petnajst filoloških razprav istega avtorja je zbrano v knjigi Paralele: slovensko-madžarska literarna srečanja, ki je izšla v Mariboru v zbirki Slavističnega društva Zora (Lukács 2006). Študije so razporejene v pet poglavij. Prvi dve poglavji z naslovom Madžarska slovenistika in Slovenska hungaristika obravnavata vprašanja recepcije, tretje poglavje se ukvarja s prekmurskim slovstvom, četrto s Prešernom in Cankarjem, peto pa preučuje paralelizme slovenske, madžarske in hrvaške literarne zgodovine. Slovensko-madžarsko-hrvaške literarne povezave preučuje tudi István Lőkös v knjigi Horvát-szlovén-magyar irodalom- és müvelödéstörténeti interferenciák (Hrvaško-slovensko-madžarske literarnozgodovinske in kulturnozgodovinske interference, Lőkös 2002). Knjiga je zbirka avtorjevih že objavljenih razprav. Njegova študija Erasmustól a reformációig: a magyar és a szlovén bibliafordítások történetének párhuzamairól (Od Erazma do reformacije: o paralelizmih zgodovine madžarskih in slovenskih prevodov Biblije) obravnava razvoj slovenske in madžarske reformacije ter prevode Biblije protestantskih piscev.

Posebno vprašanje v raziskovanju slovensko-madžarskih stikov predstavlja poimenovanje Slovencev, živečih na območju nekdanje Ogrske. Literatura, ki se ukvarja s to problematiko, je obsežna, toda precej kaotična in neenotna, zgodovinsko in politično pogojena. Knjiga Košičevega sklada $A$ vend kérdés (Vendsko vprašanje) (Lukács 1996) je izbor spisov o ogrskih Slovencih in njihovem jeziku, nastalih v obdobju od 18. stoletja do druge polovice 20. stoletja. $\mathrm{S}$ pomočjo knjige dobi bralec vpogled $\mathrm{v}$ to, kako so pisci $\mathrm{v}$ preteklih več kot 
dvesto letih, med nenehno spreminjajočimi se zgodovinskimi in političnimi okoliščinami, presojali t. i. vendsko vprašanje.

Na področju jezikoslovja je v zbirki Oddelka za slovansko filologijo Filozofske fakultete Univerze Loránda Eötvösa Opera Slavica Budapestinensia Linguae Slavicae izšla monografija Marka Jesenška Prekmuriana: fejezetek a szlovén nyelv történetéböl (Prekmuriana: poglavja iz zgodovine slovenskega jezika) (Jesenšek 2010) v prevodu Marije Bajzek ter Györgya B. Lukácsa. Jesenškova monografija obravnava razvoj in oblikovanje slovenskega jezika, pri tem pa opozarja, da sta pred poenotenjem slovenskega knjižnega jezika v 19. stoletju obstajali dve knjižni jezikovni normi, osrednje- in vzhodnoslovenska, slednja pa se je izoblikovala $\mathrm{v}$ panonskem jezikovnem prostoru in ima dve različici, prekmursko in vzhodnoštajersko.

$\mathrm{Z}$ zgodovino slovenskega in prekmurskega slovaropisja se ukvarja Marija Bajzek. Leta 2004 je objavila razpravo A szlovén szótárirodalom (Slovensko slovaropisje) (Bajzek 2004), ki je izšla v knjigi Kis szláv lexikográfia (Mala slovanska leksikografija). Avtorica podaja pregled slovenskega slovaropisja od prvih glosarjev v srednjeveških rokopisih do sodobnih slovarjev. V posebnih poglavjih se ukvarja $\mathrm{z}$ etimološkimi slovarji in s slovarji prekmurščine ter $\mathrm{z}$ dvojezičnimi slovensko-madžarskimi in madžarsko-slovenskimi slovarji. V razpravi Narečni slovarji in prekmurščina v njih (Bajzek 2009a) pa predstavlja narečno slovaropisje in delež prekmurskega narečnega besedišča $\mathrm{v}$ različnih slovarjih.

V slovensko-madžarskih jezikovnih stikih sta zelo pomembni vprašanji dvojezičnosti in manjšinskih jezikov v Prekmurju in Porabju. S to problematiko se ukvarja Elizabeta Bernjak, gostujoča profesorica Katedre za slovenski jezik in književnost Zahodnomadžarske univerze v Sombotelu, v knjigi Slovenščina in madžarščina v stiku: sociolingvistične in kontrastivne študije (Bernjak 2004).

Zanimanje za zgodovino Slovencev je razvidno predvsem na dveh področjih: (1) dogajanja, ki so povezana z osamosvojitvijo Slovenije in (2) zgodovina slovenske manjšine na Madžarskem. Leta 1998 je izšla monografija Az önálló és demokratikus Szlovénia létrejötte (Szilágyi 1998) o nastanku samostojne in demokratične Slovenije, ki predstavlja dogodke v Sloveniji od leta 1986, ko so se pojavile prve misli o samostojnosti, do nastanka samostojne države. Po Szilágyijevem mnenju je za razumevanje političnih dogodkov tega obdobja potrebno poznati tudi pomembnejše dogodke iz preteklosti (Szilágyi 1998: 11), zato podaja pregled zgodovine Slovencev od nastanka Države Slovencev, Hrvatov in Srbov leta 1918. Szilágyi (2003) obravnava volitve ter strankarski sistem prvega destletja samostojne Slovenije v študiji Törésvonalak az önálló Szlovéniában 1991-2001 (Razpoke v samostojni Sloveniji 1991-2001), s tem pa se ukvarja tudi György B. Lukács (2010) - njegova razprava $A$ rendszerváltás szlovén útja (Slovenska pot spremembe političnega sistema) preučuje spremembo političnega sistema, njene vzroke, osamosvajanje ter spremembo slovenskega ekonomskega sistema.

Povojno zgodovino slovenske manjšine v Porabju obravnava dvojezična knjiga Ferenca Stipkovitsa (1994) Porabski Slovenci: dodatki k zgodovini porabskih 
Slovencev 1945-1949. Stipkovits se dotakne vprašanj madžarske narodnostne politike, narodnostnih šol in položaja manjšine v Porabju po drugi svetovni vojni. Pregled zgodovine Prekmurja podaja dvodelna dvojezična knjiga Viri za zgodovino Prekmurja (Mayer-Molnár 2008). Zbirka arhivskih dokumentov je nastala v sodelovanju Arhivov Železne in Zalske županije. V prvem delu so zbrani viri iz obdobja med letoma 871 in 1849, v drugem delu pa iz obdobja med letoma 1850 in 1921. Zbirka je dragocen vir za zgodovinarje in za vse, ki jih zanima zgodovina Prekmurja.

\section{Slovarji, učbeniki, študijska gradiva}

Madžarskim študentom slovenistike in vsem, ki se učijo slovenščino, so dosegljivi dvojezični slovarji Jožeta Hradila (1996, 1998) in Elizabete Bernjak (1995) pa tudi slovarji madžarskih slovenistov in slovaropiscev. István Lukács (1991) je v Budimpešti izdal slovarček Szlovén-magyar szótár (Slovensko-madžarski slovar), ki je priloga učbenika madžarščine za tujce Színes magyar nyelvkönyv (Uhrman 1990). Dve leti kasneje je Zveza Slovencev na Madžarskem izdala madžarsko-slovenski frazeološki slovar Franceka Mukiča (1993), trojezični slovar istega avtorja, Porabsko-knjižnoslovensko-madžarski slovar (Mukič 2005) pa je izšel leta 2005 prav tako v izdaji Zveze Slovencev na Madžarskem. Slovar predstavlja besedišče porabskega slovenskega narečja $\mathrm{Z}$ zgledi in s knjižnoslovenskimi in madžarskimi ustreznicami v posebnih stolpcih. Dragocen prispevek k raziskovanju porabskega narečja je Slovar Gornjega Senika A-L Marije Bajzek (2009b), ki je izšel v Mariboru v zbirki Slavističnega društva Zora. Slovar predstavlja besedje gornjeseniškega slovenskega govora. Narečnim besedam sledijo razlage $\mathrm{v}$ knjižni slovenščini, fonetično zapisani zgledi ter madžarske in nemške ustreznice. V slovarju so zajeti tudi frazemi, lastna imena ter terminološke besede s področja kmetijstva in obrti. Leta 1996 je Zveza Slovencev na Madžarskem izdala dvojezični Etnološki slovar Slovencev na Madžarskem Marije Kozar (1996). Slovar predstavlja »etnološke značilnosti slovenskega Porabja v novejšem času« (Kozar 1996: 4). Obdelani so »predmeti in pojavi snovne, duhovne in družbene kulture Slovencev na Madžarskem v 20. stoletju po 36 tematskih skupinah«, kakršne so na primer poljedelstvo, živinoreja, ribolov, prehrana, noša, glasba, ples itd. (Kozar 1996: 12). V geselskem članku je iztočnica v knjižni slovenščini, tej v oklepaju sledijo porabske ustreznice in razlaga v knjižni slovenščini. Geslu v slovenščini sledi isto geslo v madžarščini. Slovarsko gradivo ponazarjajo tudi risbe predmetov in pojavov.

Profesorji Inštituta za slavististiko in baltistiko Filozofske fakultete v Budimpešti so pripravili kvalitetno študijsko gradivo Szláv civilizáció ${ }^{2}$ (Slovanska civilizacija) in tako postavili temelje za znanje študentov slavistike na prvi stopnji študija. V gradivu so zbrane najpomembnejše informacije s področja li-

\footnotetext{
${ }^{2}$ vir: http://szlavintezet.elte.hu/szlavtsz/slav_civil/main.html (datum: 25. 03. 2012)
} 
terature, jezika in zgodovine različnih slovanskih narodov. Zgodovino slovenske književnosti sta sestavila István Lukács in Mladen Pavičić - pregled obravnava slovensko slovstvo od Brižinskih spomenikov do sodobne literature. Jezikovni del je delo Marije Bajzek in Mladena Pavičića - opis slovenskega jezika daje poleg obsežnega slovničnega dela vpogled v zgodovino, današnji položaj in $\mathrm{v}$ narečno razčlenjenost slovenskega jezika, povzame pa tudi zgodovino slovenske leksikografije. Imre Szilágyi, avtor zgodovinskega dela, obravnava zgodovino Slovencev od priselitve slovanskih plemen na ozemlje današnje Slovenije v 6. stoletju do osamosvojitve in nastanka samostojne Slovenije. Celotno gradivo je dosegljivo na spletni strani Inštituta.

Študentom prve in druge stopnje so v pomoč tudi štirje že objavljeni deli dvojezične antologije slovenske književnosti Szlovén irodalmi antológia. Antologije so izšle v zbirki Oddelka za slovansko filologijo Filozofske fakultete Univerze Loránda Eötvösa Opera Slavica Budapestinensia Litterae Slavicae pod uredništvom Marije Bajzek, Istvána Lukácsa in Mladena Pavičića v letih 2007, 2008, 2009 in 2010. Vsaka knjiga vsebuje dela najpomembnejših slovenskih pesnikov in pisateljev ter madžarske prevode del iz različnih obdobij. Prva knjiga se ukvarja $\mathrm{z}$ literarno produkcijo $\mathrm{v}$ obdobju od začetkov slovenskega slovstva do konca 19. stoletja, $v$ drugi knjigi so zbrana dela iz prve polovice, $\mathrm{v}$ tretji in četrti knjigi pa iz druge polovice 20. stoletja. Gre za dragoceno zbirko, njeni uredniki pa bi morali nadaljevati odlično zastavljeno delo.

\section{Slovenska manjšinska knjižna produkcija}

Organizacija Zveza Slovencev na Madžarskem je bila ustanovljena leta 1990. Med različnimi dejavnostmi Zveze je treba omeniti njeno bogato založniško dejavnost. Od leta 1991 izhaja tednik Porabje v porabskem narečju in v knjižni slovenščini ter letopis Slovencev na Madžarskem Slovenski koledar (od leta 2009 Porabski koledar). Leta 1990 je izšla slovensko-madžarska dvojezična zbirka ljudskih pravljic Karla Krajcarja Slovenske pravljice iz Porabja. K ohranitvi porabskega slovenskega ljudskega izročila sta prispevala tudi Dušan in Francek Mukič z zbirko Füčkaj, füčkaj, fantiček moj: sto ljudskih pesmi iz Porabja 1-2 (Mukič 2001, 2003). V sodelovanju Zveze Slovencev na Madžarskem in založbe Franc-Franc je bila objavljena dvojezična zbirka andovskih ljudskih pripovesti Andovske zgodbe (Holec 2003). Zgodbe v porabskem narečju je zbral Karel Holec, v knjižno slovenščino pa jih je prevedel Milan Vincetič. Prisotnost ljudskega izročila je precej močna tudi v knjigi Srebrni breg/Srebrni brejg. Zbirko kratke proze treh prekmurskih piscev, Ferija Lainščka, Milana Vincetiča in Milivoja Roša, je Zveza izdala leta 1995. Zgodbe o otroštvu so natisnjene tako v knjižni slovenščini kot v prekmurskem narečju. Porabska pisateljica Irena Barber je $\mathrm{v}$ devetdesetih letih prejšnjega stoletja izdala narečno kratko prozo v dveh knjigah: leta 1993 je izšla Trnova paut: pripovesti pa zgodbe, leta 1998 pa Življenje je kratko z istim podnaslovom, obe napisani v porabskem narečju. Roman Franceka Mukiča Garaboncijaš je izšel 
leta 2005 v Murski Soboti pri založbi Franc-Franc. Avtorjev madžarski prevod tega romana je tri leta kasneje objavila Zveza Slovencev na Madžarskem. Leta 2006 je izšla pod uredništvom Andrása Bertalana Székelya antologija sodobne prekmurske in porabske slovenske literature v prevodu Judit Zágorec-Csuka (A muravidéki és rábavidéki kortárs szlovén irodalom antológiája). Zanimiv prispevek $\mathrm{k}$ preučevanju porabskega vsakdanjika ter stvarnosti je esejistična zbirka Valerije Perger, svetovalke za zamejsko šolstvo v Porabju, Tudi to je slovensko Porabje (Perger 1995).

\section{Slovensko leposlovje v madžarskem prevodu}

Najboljši madžarski prevajalci slovenskega leposlovja so Orsolya Gállos, Klára Körtvélyessy, Judit Reiman, László Lator, Dezső Tandori, Roland Orcsik, Gábor Lanczkor, Gábor Csordás, Zoltán Csuka ter Zsolt Lukács. Največkrat prevajajo Draga Jančarja - njegova dela posreduje madžarskim bralcem predvsem Orsolya Gállos. Poleg Jančarjevih romanov in kratkih zgodb prevaja Gálloseva tudi njegove eseje, ki jih redno objavljajo različne madžarske revije. V obravnavanem obdobju so v madžarskem prevodu knjižno izšla naslednja Jančarjeva dela: Posmehljivo poželenje (Kaján vágyak, 1997a), Pogled angela (Az angyal pillantása, 1997 b - skupaj s Kláro Körtvélyessy in Judit Reiman), Zvenenje v glavi (Zajgás a fejben, 2001), Katarina, pav in jezuit (Katarina, a páva és a jezsuita, 2006) ter Drevo brez imena (A névtelen fa, 2011). Poleg Jančarja je Orsolya Gállos prevedla tudi Kovičev roman Profesor domišljije (Képzelet tanár úr, 2006), otroški roman Ferija Lainščka Velecirkus Argo (Argo Nagycirkusz, 1999), zbirko kratkih zgodb Mojce Kumerdej Fragma (Fragma, 2008) in Kocbekove novele Strah in pogum (Félelem és bátorság, 1990). Najnovejši prevod Orsolye Gállos, roman Bilijard v Dobrayju Dušana Šarotarja (Biliárd a Dobray szállóban), bo kmalu izšel. Izmed prevodov slovenskih proznih del je treba omeniti Kovičev roman Pot $v$ Trento in Bartolov roman Alamut, ki ju je prevedla Klára Körtvélyessy (Utazás Trentóba, 1998; Alamut, 2005), roman Aleša Čara Pasji tango v prevodu Gáborja Lanczkorja (Kutyatangó, 2006), roman Ferija Lainščka Ki jo je megla prinesla $\mathrm{v}$ prevodu Judit Gordos in Alberta Halásza (Akit a köd hozott, 1996), zbirko kratkih zgodb Andreja Blatnika Menjave kož v prevodu Orsolye Gállos in Judit Reiman (Bör, 2002) ter antologijo slovenske sodobne kratke proze $A z$ első nap (Prvi dan, 2002 - prevedle Orsolya Gállos, Klára Körtvélyessy in Judit Reiman). Veliko je bila prevajana tudi slovenska poezija, največkrat France Prešeren, Kajetan Kovič, Tomaž Šalamun, Edvard Kocbek, Aleš Debeljak, Primož Čučnik, Aleš Šteger, Srečko Kosovel, Dane Zajc ter Taja Kramberger. S področja slovenske esejistike so v madžarskem prevodu izšle zbirke esejev Aleša Debeljaka, Mitje Čandra, Edvarda Kocbeka ter antologija slovenskih esejev Az eltört korsó v uredništvu Orsolye Gállos (Razbiti vrč, 1992). Prav tako je bogata tudi prevedena literatura, ki je objavljena revialno. Nekatere revije včasih posvetijo posebno številko Sloveniji in slovenski literaturi, kot na primer revija Napút leta 2004, revija Jelenkor leta 2002 in 2004 ter revija Tiszatáj leta 1992. 


\section{Slovenistika na Oddelku za slovansko filologijo Filozofske fakultete Univerze Loránda Eötvösa v Budimpešti}

Slovenistika se na Madžarskem poučuje na univerzah v Budimpešti in Sombotelu - na Oddelku za slovansko filologijo Filozofske fakultete Univerze Loránda Eötvösa v Budimpešti zgodovina slovenističnih študijev sega na začetek 20. stoletja. Prva pomembnejša dogodka sta bila diploma in doktorat Avgusta Pavla na Slavističnem oddelku v letih 1909 in 1913. Na začetku petdesetih let so se tukaj izobraževali učitelji za porabske šole (Pavičić 2009b: 291). Po dolgem odmoru je leta 1981 začel delovati lektorat slovenskega jezika, v tem času vključen v srbokroatistično katedro (Pavičić 1998: 140). Prvi lektor je bil Vlado Nartnik, leta 1986 mu je sledila Marjanca Mihelič, od leta 1992 opravlja lektorske naloge Mladen Pavičić. Zelo pomembna je v zgodovini madžarske slovenistike letnica 2006, ko se je na Oddelku za slovansko filologijo začel samostojen slovenistični študij. Prvi profesorji so bili István Lukács (književnost), Marko Jasenšek, gostujoči profesor iz Maribora (jezikoslovje) ter Mladen Pavičić. Od leta 2009 predava jezikoslovne predmete Marija Bajzek. Budimpeštanska slovenistika sodeluje pri projektih Svetovni dnevi Centra za slovenščino kot drugi/tuji jezik. Leta 2005 in 2008 se je lektorat udeležil projektov Svetovni dnevi slovenskega filma in Svetovni dnevi slovenske literature na filmu. Leta 2010 so študentje slovenistike v okviru projekta Svetovni dnevi sodobne slovenske literature prevajali sodobna slovenska literarna dela, kratko prozo, poezijo, odlomke romanov in svoje prevode predstavili na literarnem večeru lektorata. Na katedri smo sprejeli številne goste, slovenske literate, med drugimi Lucijo Stupica, Mojco Kumerdej, Draga Jančarja, Primoža Čučnika, Matjaža Zupančiča, Aleša Čara, Aleša Štegra, Gabrielo Babnik, Tadeja Goloba in Dušana Šarotarja, madžarske prevajalce Orsolyo Gállos, Lászla Latorja in Kláro Körtvélyessi ter slovenske profesorje Zinko Zorko, Martina Orožen, Mihaelo Koletnik, Natalijo Ulčnik, Marka Jesenška in Vincenca Rajšpa ter pomožnega mariborskega škofa Jožefa Smeja.

\section{LITERATURA}

Marija BAJZEK, 1992: Življenje Slovencev med Muro in Rabo. Budapest: Kossics Alapítvány.

Marija BAJZEK LUKAČ, 2009a: Narečni slovarji in prekmurščina v njih. Studia Slavica Savariensia 2009/1-2, 189-196.

- -, 2009b: Slovar Gornjega Senika A-L. Maribor: Mednarodna založba Oddelka za slovanske jezike in književnosti, Filozofska fakulteta.

Mária BAJZEK LUKÁCSNÉ, 2004: A szlovén szótárirodalom. Kis szláv lexikográfia. Ur. István Nyomárkay, István Víg. Budapest: ELTE BTK Szláv Filológiai Tanszék. 
Mária BAJZEK, István LUKÁCS, Mladen PAVIČIĆ 2007: Szlovén irodalmi antológia I. Budapest: ELTE BTK Szláv Filológiai Tanszék.

Irena BARBER, 1993: Trnova paut: pripovesti pa zgodbe. Szombathely: Zveza Slovencev na Madžarskem.

- -, 1998: Življenje je kratko: pripovesti pa zgodbe. Szombathely: Zveza Slovencev na Madžarskem.

Vladimir BARTOL, 2005: Alamut. Budapest: Európa.

Elizabeta BERNJAK, 2004: Slovenščina in madžarščina v stiku: sociolingvistične in kontrastivne študije. Maribor: Slavistično društvo.

- -, 1995: Madžarsko-slovenski, slovensko-madžarski slovar. Ljubljana: Cankarjeva založba.

József BOKOR, Imre SZÍJÁRTÓ, 2001: Szomszéd népek - szomszédos kultúrák. Maribor: Pedagoška fakulteta.

Andrej BLATNIK, 2002: Bör. Budapest: JAK.

Mitja ČANDER, 2002: Az első nap: kortárs szlovén elbeszélők. Pécs: Jelenkor.

Aleš ČAR, 2006: Kutyatangó. Budapest: JAK: L'Harmattan.

Orsolya GÁLLOS, 1992: Az eltört korsó: válogatás a legújabb szlovén esszéirodalomból. Pécs: Jelenkor.

Karel HOLEC, 2003: Andovske zgodbe. Murska Sobota: Franc-Franc.

Jože HRADIL, 1996: Slovensko-madžarski slovar. Ljubljana: DZS.

- -, 1998: Madžarsko-slovenski slovar. Murska Sobota: Pomurska založba.

Drago JANČAR, 1997a: Kaján vágyak. Budapest: Osiris 2000.

- -, 1997b: Az angyal pillantása. Pécs: Jelenkor.

- -, 2001: Zajgás a fejben. Pécs: Jelenkor.

--, 2006: Katarina, a páva és a jezsuita. Pécs: Jelenkor.

- -, 2011: A névtelen fa. Budapest: L'Harmattan.

Marko JESENŠEK, 2010: Prekmuriana. Poglavja iz zgodovine slovenskega jezika. Budapest: Balassi.

Edvard KOCBEK, 1990: Félelem és bátorság: Négy novella. Újvidék: Forum; Budapest: Európa.

Marija KOZAR, 1996: Etnološki slovar Slovencev na Madžarskem. Monošter: Zveza Slovencev na Madžarskem.

Kajetan KOVIČ, 2006: Képzelet tanár úr: ljubljanai történet. Pécs: Alexandra.

--, 1998: Utazás Trentóba: jelenetek Franc M. egyszerü életéből. Budapest: Európa.

Mojca KUMERDEJ, 2008: Fragma. Budapest: L'Harmattan.

Feri LAINŠČEK, 1996: Akit a köd hozott. Budapest: Seneca.

- -, 1999: Argo Nagycirkusz: regény. Lendva: Studio Arts. 
Feri LAINŠČEK, Milivoj ROŠ, Milan VINCETIČ, 1995: Srebrni breg/Srebrni brejg. Szombathely: Zveza Slovencev na Madžarskem.

István LÖKÖS, 2002: Horvát-szlovén-magyar irodalom- és müvelödéstörténeti interferenciák. Budapest: Lucidus.

István LUKÁCS, István FRIED, 1998: Hasonlóságok és különbözöségek-Ujemanja in razhajanja. Budapest: Kossics Alapítvány.

István LUKÁCS, István NYOMÁRKAY, 1998: Slovensko-madžarski jezikovni in književni stiki od Košiča do danes. Budapest: Kossics Alapítvány.

István LUKÁCS, 1991: Szlovén-magyar szótár. Budapest: NHK.

- -, 1996: A vend kérdés. Budapest: Kossics Alapítvány.

- -, 2001: A megváltó Mátyás király szineváltozásai a szlovén néphagyományban és szépirodalomban. Budapest: Lucidus.

- -, 2005: Közel s távol. Szlovén-magyar irodalomtörténeti tanulmányok. Budapest: ELTE BTK Szláv Filológiai Tanszék.

- -, 2006: Paralele. Slovensko-madžarska literarna srečanja. Maribor: Slavistično društvo.

István LUKÁCS, Mladen PAVIČIĆ, 2008: Szlovén irodalmi antológia II. Budapest: ELTE BTK Szláv Filológiai Tanszék.

György LUKÁCS B., 2010: A rendszerváltás szlovén útja. Rendszerváltás és történelem. Tanulmányok a kelet-európai átalakulásról. Ur. Tamás Krausz, Miklós Mitrovits, Csaba Zahorán. Budapest: L’Harmattan - ELTE BTK Kelet-Európa Története Tanszék.

László MAYER, András MOLNÁR, 2008: Viri za zgodovino Prekmurja: zbirka dokumentov 1-2. Szombathely: Vas Megyei Levéltár; Zalaegerszeg: Zala Megyei Levéltár.

Marjanca MIHELIČ, 1990: K madžarski slovenistiki od Avgusta Pavla dalje. Slavistična revija 38/1, 69-76.

- -, 1998: K madžarski slovenistiki od Avgusta Pavla dalje. Hasonlóságok és különbözöségek - Ujemanja in razhajanja. Ur. István Lukács, István Fried. Budapest: Kossics Alapítvány. 193-200.

Dušan MUKIČ, Francek MUKIČ, 2001: Füčkaj, füčkaj, fantiček moj: sto ljudskih pesmi iz Porabja 1. Szombathely: Zveza Slovencev na Madžarskem.

- -, 2003: Füčkaj, füčkaj, fantiček moj: sto ljudskih pesmi iz Porabja 2. Szombathely: Zveza Slovencev na Madžarskem.

Francek MUKIČ, 2005: Porabsko-knjižnoslovensko-madžarski slovar. Szombathely: Zveza Slovencev na Madžarskem.

- -, 2005: Garaboncijaš. Murska Sobota: Franc-Franc.

Ferenc MUKICS, 1993: Magyar-szlovén frazeológiai szótár. Szombathely: Magyarországi Szlovének Szövetsége.

- -, 2008: A garabonciás. Szentgotthárd: Magyarországi Szlovének Szövetsége.

Roland ORCSIK, 2010: Kalandozás a szerb, horvát, szlovén irodalomban. Bárka 18/1, 77-83. 
Mladen PAVIČIĆ, 1998: Prispevek za zgodovino poučevanja slovenščine na budimpeštanski slavistiki. Slovensko-madžarski jezikovni in književni stiki od Košiča do danes. Ur. István Lukács, István Nyomárkay. Budapest: Kossics Alapítvány. 139-145.

--, 2009a: Szlovén irodalmi antológia III. Budapest: Balassi Kiadó.

--, 2009b: Infrastruktura slovenistike na Filozofski fakulteti Univerze Loránda Eötvösa. Obdobja 28: Infrastruktura slovenščine in slovenistike. Ur. Marko Stabej. Ljubljana: Znanstvena založba Filozofske fakultete.

- -, 2010: Szlovén irodalmi antológia IV. Budapest: Balassi Kiadó.

Valerija PERGER, 1995: Tudi to je slovensko Porabje. Monošter: Zveza Slovencev na Madžarskem.

Ferenc STIPKOVITS, 1994: Porabski Slovenci: dodatki k zgodovini porabskih Slovencev 1945-1949. Celldömölk: Módszertani Szakcsoport.

András Bertalan SZÉKELY, 2006: A muravidéki és rábavidéki kortárs szlovén irodalom antológiája. Budapest; Szentgotthárd: Magyar-Szlovén Baráti Társaság.

Imre SZILÁGYI, 1998: Az önálló és demokratikus Szlovénia létrejötte. Budapest: Teleki L. Alapítvány.

- -, 2003: Törésvonalak az önálló Szlovéniában 1991-2001. Nemzeti és regionális identitás Közép-Európában. Ur. Barna Ábrahám, Ferenc Gereben, Rita Stekovics. Piliscsaba: PPKE BTK. 499-506.

Szláv civilizáció. vir: http://szlavintezet.elte.hu/szlavtsz/slav_civil/main.html (datum: 25. 3. 2012)

Szlovén szépirodalom magyar nyelven. vir: http://szlavintezet.elte.hu/szlavtsz/szloven/ irodalom.shtml (datum: 25. 3. 2012)

György UHRMAN, 1990: Szines magyar nyelvkönyv: egységes jegyzet külföldiek részére. Budapest: Tankönyvkiadó.

József VARGA, Zoltán MOLNÁR, 1991: Corvin Mátyás-konferencia: tudományos tanácskozás Mátyás király halálának 500. évfordulóján. Maribor: Pedagoška fakulteta.

Zinka ZORKO, Marija BAJZEK, István LUKÁCS, 1994: Košič in njegov čas. Budapest: Kossics Alapítvány.

\section{THE ACHIEVEMENTS OF THE SLOVENE STUDIES IN HUNGARY FROM 1990 UNTIL NOW - AN OVERVIEW}

In the past two decades, a lot of papers have been published in Hungary which deal with the issues of the Slovene Studies. There has been no study published yet to present the achievements of the Slovene Studies in Hungary in a systematic, comprehensive manner. The following paper tries to fulfil this gap, presenting the most important publications within this area. In the past two decades, vivid interest was shown towards the Sloveno-Hungarian literary, linguistic and cultural connections. Many conferences were organized, and many books were published on these subjects. The researches within 
Literary History mostly deal with literary parallels and the history of reception. As for the linguistics, most publications deal with the Pomurje-Porabje dialect, the bilinguism and the minority language usage in Hungary. The historians mostly researched the events pertaining to the formation of the independent state of Slovenia. In my paper, I am going to deal with the publications on Literary History, Linguistics, History of Culture and History, I am going to present the dictionaries, language books and other teaching aids, I am going to provide an overview on the scientific and literary publications of the Association of Slovenes in Hungary, and, in conclusion, I am going to sum up the artistic translations from Slovene into Hungarian. 